Ambiente \& Água - An Interdisciplinary Journal of Applied Science
ISSN 1980-993X - doi:10.4136/1980-993X
www.ambi-agua.net
E-mail: ambi-agua@agro.unitau.br

\title{
Avaliação do comportamento da umidade do solo em áreas de eucalipto e de floresta nativa
}

\author{
doi: 10.4136/ambi-agua.1419
}

Received: 16 Aug. 2013; Accepted: 09 Dec. 2013

\section{Geberson Ricardo de Paula $^{1^{*}}$; Getulio Teixeira Batista1; Marcelo dos Santos Targa ${ }^{1}$; Claudinei Fonseca Souza ${ }^{2}$; Nelson Wellausen Dias ${ }^{3}$; José Geanini Peres ${ }^{2}$}

\author{
${ }^{1}$ Programa de Pós-Graduação em Ciências Ambientais - Universidade de Taubaté -UNITAU, SP \\ ${ }^{2}$ Centro de Ciências Agrárias, Departamento de Recursos Naturais e Proteção Ambiental - Universidade Federal \\ de São Carlos - UFScar, Araras, SP \\ ${ }^{3}$ Fundação Instituto Brasileiro de Geografia e Estatística - FIBGE, Aracaju, SE \\ *Autor correspondente: e-mail: geberslp@gmail.com, \\ gtbatista@gmail.com, targa.marcelo@gmail.com, claudinei.souza@gmail.com,nwdias@gmail.com, \\ jogepe@cca.ufscar.br
}

\section{RESUMO}

Áreas ocupadas com pastagem vêm sendo substituídas por plantações de eucalipto, o que modifica a paisagem, a economia regional, e a dinâmica da água nos solos. Assim, o presente trabalho teve por objetivo avaliar o comportamento da água em Latossolo Vermelho-Amarelo em duas coberturas vegetais, uma plantação de eucalipto, de seis anos de idade, e uma floresta nativa, em processo de regeneração há vinte anos. O estudo foi desenvolvido na bacia hidrográfica do rio Una, no período de junho de 2009 a abril de 2011. Foram instalados 96 sensores de umidade (Watermark ${ }^{\mathrm{TM}}$ ), nas profundidades de 20,60, e $120 \mathrm{~cm}$. Foi observado que, quando da ocorrência de precipitação pluvial, as camadas superficial e intermediária tiveram a umidade aumentada, o mesmo não ocorrendo na camada mais profunda. Verificouse que houve diferença entre a umidade do solo medida nas áreas de eucalipto e de floresta nativa e que em todo o período estudado a umidade se manteve entre a Capacidade de Campo e o Ponto de Murchamento Permanente, não havendo restrição de água. A temperatura da copa do eucalipto se manteve mais baixa, indicando que nele a taxa de evapotranspiração foi maior. As diferenças na umidade podem ser explicadas pela diferença entre as propriedades físicas dos solos nas áreas estudadas, pois embora elas tenham a mesma inclinação, recebam mesma insolação e estejam próximas uma da outra, o solo coberto com eucalipto apresentou uma Capacidade de Armazenamento de Água 63\% superior à área com floresta nativa. Foi também observado que toda precipitação pluvial que atingiu a superfície do solo, nele infiltrou, não tendo ocorrido escoamento superficial em nenhuma das duas áreas estudadas. Concluiu-se que os resultados desta pesquisa fornecem indícios importantes sobre diferenças no comportamento da água no solo em áreas cobertas com floresta nativa e Eucalyptus e por essa razão, sugerem-se novos estudos com maior abrangência geográfica, em áreas pareadas com diferentes declividades, faceamentos e tipos de solo.

Palavras-chave: Una, sensor de umidade, infiltração, escoamento superficial. 


\title{
Evaluation of the behavior of water in soil under eucalipto and native forest covers
}

\begin{abstract}
Areas occupied by grasslands have been replaced by eucalyptus plantations, which modifies the landscape, the regional economy, and water dynamics in soils. Thus, this study aimed to evaluate the behavior of water in Oxisol in two vegetation land covers, a six years old eucalyptus plantation, and a native forest in regeneration process for twenty years. The study was developed in the Una River Basin from June 2009 to April 2011. Ninety six moisture sensors were installed (Watermark ${ }^{\mathrm{TM}}$ ) at depths of 20,60 , and $120 \mathrm{~cm}$. It was observed that, upon the occurrence of rainfall, the superficial and intermediate layers had increased humidity, which did not occur in the deepest layer. It was found that there were differences in soil moisture measured in the areas of eucalyptus and native forest and throughout the study period humidity was maintained between field capacity and permanent wilting point, with no water restriction. Canopy temperature of the eucalyptus plantation remained lower, indicating that its evapotranspiration was higher than in the forest area. The differences in moisture can be explained by the difference between the physical properties of soils in the study areas, because although they have the same slope, receive the same insolation and are close to each other, soil covered by eucalyptus presented a water storage capacity $63 \%$ above the area with native forest. It was also observed that all rainfall reaching the soil surface infiltrated and there was no runoff in the two areas studied. It was concluded that the results of this research provide important insights about differences in the behavior of water in the soil when covered by eucalyptus or native forest. For this reason, we suggest further studies with greater geographic reach in paired areas with different slopes, aspects and soil types.
\end{abstract}

Keywords: Una, humidity sensor, infiltration, runoff.

\section{INTRODUÇÃO}

A região do Vale do Paraíba, no estado de São Paulo, possui potencial para a expansão do cultivo do eucalipto em função do seu clima e da disponibilidade de grandes áreas ocupadas por pastagens degradadas. Esta alteração na cobertura vegetal da região de pastagem para eucalipto poderá ocasionar impacto na paisagem, na economia regional e na dinâmica da água no sistema solo-planta-atmosfera (Lima, 1996).

A água é extremamente importante na produção vegetal e seu manejo racional, como forma de evitar a sua falta ou excesso, é decisivo para o pleno desenvolvimento das plantas e para a preservação do meio ambiente. Por ser o solo, um reservatório aberto para a atmosfera e para os horizontes ou camadas mais profundas, torna-se importante a quantificação de elementos da fase terrestre do ciclo hidrológico, tais como a capacidade de armazenamento, os fluxos que ocorrem tanto na superfície como a infiltração e a evaporação, quanto nas camadas mais profundas do solo.

É fundamental se analisar o comportamento da água no solo com cobertura de eucalipto e outras coberturas vegetais, especialmente de floresta nativa, pois existe uma grande discussão na relação da disponibilidade hídrica em bacias hidrográficas com extensas áreas plantadas com eucalipto.

Este trabalho teve como objetivo avaliar a distribuição e o armazenamento de água no solo, nas profundidades de 20, 60 e $120 \mathrm{~cm}$, em áreas plantadas com eucalipto, em fase de crescimento, e em área de floresta nativa, em fase de regeneração, por meio do monitoramento da umidade do solo e temperatura das folhas e da superfície. 


\section{MATERIAL E MÉTODOS}

\subsection{Caracterização da área de estudo}

O presente estudo foi desenvolvido na Fazenda Una, localizada na bacia hidrográfica do rio Una (BHRU), a qual corresponde a mais de $80 \%$ da área territorial do município de Taubaté, e o restante distribuído entre os municípios de Pindamonhangaba, Tremembé e Redenção da Serra (Figura 1).

A BHRU está situada na margem direita do rio Paraíba do Sul, localizando-se entre as coordenadas $23^{\circ} 14^{\prime} 00^{\prime \prime} \mathrm{S}$ e $22^{\circ} 58^{\prime} 00^{\prime} \mathrm{S}$ e $45^{\circ} 37^{\prime} 00^{\prime} \mathrm{W}$ e $45^{\circ} 17^{\prime} 00^{\prime} \mathrm{W}$. Ela é formada pela união do ribeirão das Almas com o rio da Rocinha e seus afluentes, perfazendo uma área total de $476 \mathrm{~km}^{2}$. Ela dista $115 \mathrm{~km}$ de São Paulo-SP e $350 \mathrm{~km}$ da cidade do Rio de Janeiro-RJ (Batista et al., 2005).

De acordo com Plano das Bacias Hidrográficas do rio Paraíba do Sul (CPTI, 2004), as altitudes da BHRU oscilam entre 500 e 1.000 metros, com limite a nordeste pela Serra do Quebra Cangalha a e a sudeste pela Serra do Jambeiro.

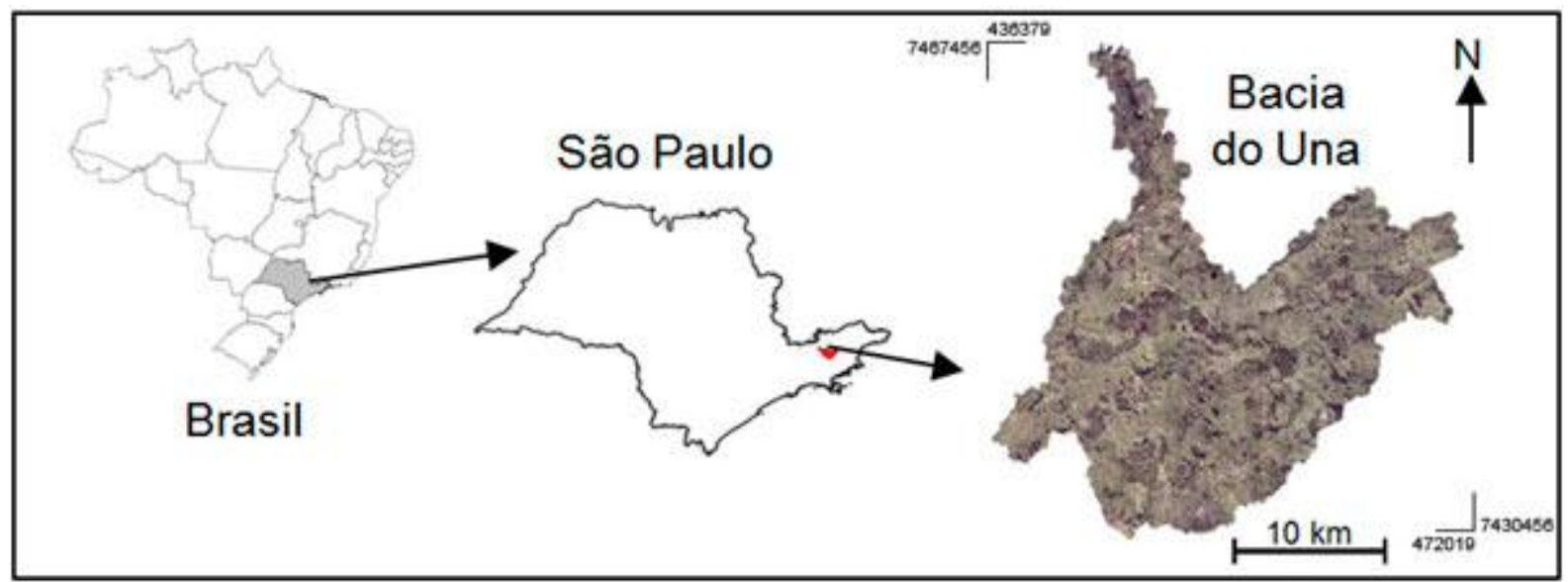

Figura 1. Localização da Bacia Hidrográfica do rio Una (BHRU), mostrada pelo mosaico de fotografias aéreas ortorretificadas de 2003 (Batista et al., 2005).

O clima da parte paulista da bacia do Paraíba do Sul, segundo Lemos (2000), é do tipo mesotérmico úmido com seca nos meses de junho a agosto e chuva nos meses de novembro a fevereiro. As características topográficas da região influenciam na distribuição pluviométrica e na temperatura locais. Nas regiões serranas as temperaturas de inverno são frequentemente abaixo de zero com geadas assíduas enquanto que, nas partes baixas da bacia, ao nível da calha do rio, podem ocorrer médias do mês de janeiro da ordem de $32^{\circ} \mathrm{C}$. A precipitação média anual (entre os anos de 1941 e 1970) variou de $1200 \mathrm{~mm}$ na região de Jacareí até 2000 mm nas regiões altas das Serra da Mantiqueira e do Mar. A Zona de Convergência do Atlântico Sul (ZCAS), durante o verão, tem um o papel importante na região causando muita nebulosidade com dias chuvosos e precipitações esparsas, resultado de sistemas frontais semiestacionários sobre a região Sudeste do país.

A Fazenda Una, pertencente à empresa Fibria S.A., localiza-se dentro da BHRU, na estrada municipal do Taboão, no Bairro do Taboão, no município de Taubaté, SP situa a uma altitude média de $728 \mathrm{~m}$ e suas coordenadas geográficas são as seguintes: $23^{\circ} 05^{\prime} 32^{\prime}$ ' $\mathrm{S}, 45^{\circ}$ 28 ' 14 " W.

A variedade de eucalipto plantada na propriedade é a Eucalyptus urograndis, em espaçamento de $3 \times 2 \mathrm{~m}$ e a floresta nativa se encontra em fase de regeneração por mais de 20 anos. 


\subsection{Caracterização físico-química dos solos}

As análises físicas e químicas do solo foram realizadas no Laboratório de Solos do Departamento de Ciências Agrárias da Universidade de Taubaté. Para a determinação da massa específica do solo e para o levantamento da curva de retenção da água no solo foram utilizadas amostras de solo indeformadas, coletadas nas profundidades de 20,60 e $120 \mathrm{~cm}$ por meio de anéis metálicos com $50 \mathrm{~cm}^{3}$ de volume.

A análise granulométrica foi realizada pelo método da pipeta (Gee e Bauder, 1986; Kiehl, 1979), utilizando como dispersante químico o hidróxido de sódio $(\mathrm{NaOH} ; 1 \mathrm{~N})$. Para a dispersão mecânica da amostra foi utilizado um agitador rotativo de baixa velocidade (35 RPM), com tempo de agitação das amostras de solo de 16 horas.

As massas específicas do solo $\left(\rho_{\mathrm{s}}\right)$ e das partículas $\left(\rho_{\mathrm{p}}\right)$ foram determinadas pelos métodos do anel volumétrico e do álcool anidro, respectivamente, de acordo com as recomendações de Ferreira et al. (1990). A porosidade total do solo $(\alpha)$ foi obtida a partir das massas específicas do solo e das partículas, de acordo com Reichardt e Timm (2004).

As curvas de retenção de água no solo que relacionam o potencial matricial da água do solo $(\Psi \mathrm{m})$ com a sua umidade volumétrica $(\theta)$ foram determinadas no Laboratório de Física de Solo do Centro de Ciências Agrárias da Universidade Federal de São Carlos, localizado em Araras, SP. Nessa determinação as amostras de solo indeformadas foram saturadas com água destilada e desaerada e então submetidas nos extratores de umidade de Richards (Klute, 1986) a pressões de $-0,01,-0,02,-0,03,-0,05,-0,1,-0,5,-1$ e $-1,5 \mathrm{MPa}$.

A umidade do solo no campo foi determinada de forma indireta utilizando-se sensores WatermarkTM (Figura 2) que medem o potencial matricial da água no solo ou tensão ( $\mathrm{kPa}$ ), o qual é convertido em umidade volumétrica $\left(\mathrm{m}^{3} / \mathrm{m}^{3}\right)$ por meio de uma curva de retenção da água do solo (TRACOM, 2004).

O sensor Watermark (Figura 2a) consiste em um sistema de medição de umidade do solo do tipo resistência elétrica, composto por dois eletrodos concêntricos, inseridos em gesso encaixado em material de matriz granular. Esses eletrodos são ligados à fiação externa que em função da umidade do solo são conectados a um leitor que transforma essa leitura de resistência elétrica em potencial de água no solo. Para facilitar o manuseio do equipamento, foram construídos tensiômetros com tubos de PVC de 3/4" nos comprimentos 30, 70 e $130 \mathrm{~cm}$ (Figura 2b). Os sensores foram colocados na ponta inferior dos tubos e a fiação dos sensores foram conduzidas pela parte interna dos tubos de PVC e posicionados na extremidade superior, onde podem ser conectados ao medidor de tensão de água no solo.

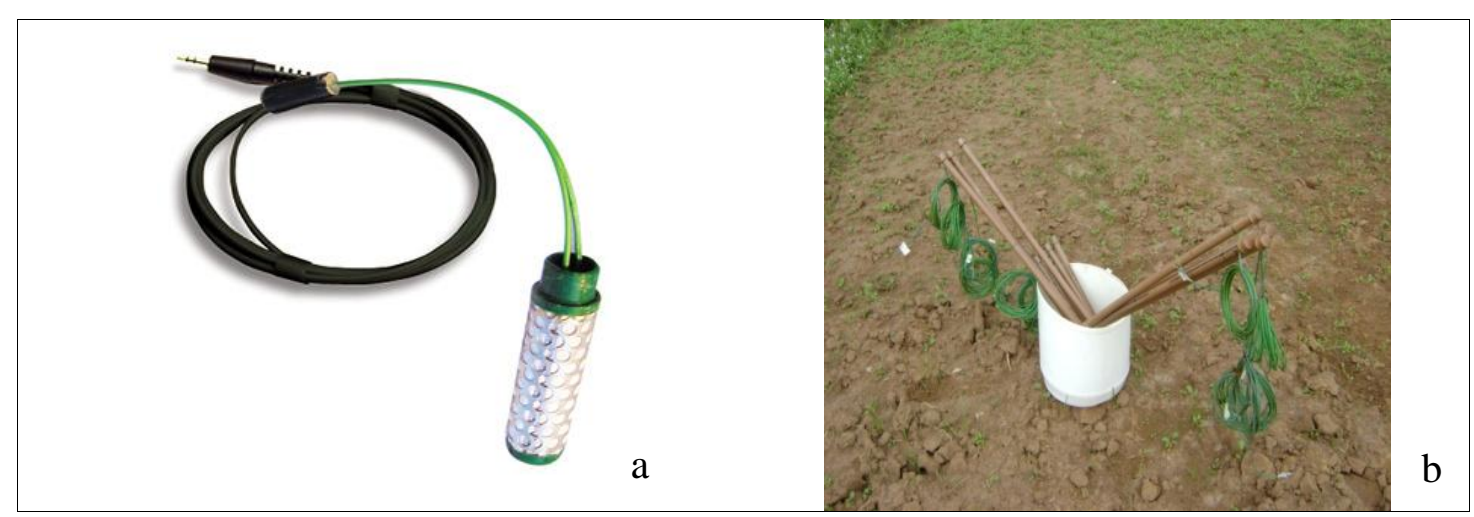

Figura 2. (a) Sensor umidade do solo WatermarkTM e (b) sensor preparado para introdução em diferentes profundidades do solo.

Os tensiômetros para monitoramento da umidade foram instalados no solo nas profundidades de 20, 60 e $120 \mathrm{~cm}$ por meio de um trado, utilizado para perfurar o solo, e distribuídos igualmente em 16 pontos, nas profundidades de 20,60 e $120 \mathrm{~cm}$, totalizando 48 
sensores em cada uma das áreas conforme Figura 3 e Figura 4a no eucalipto e Figura 4b na floresta nativa.

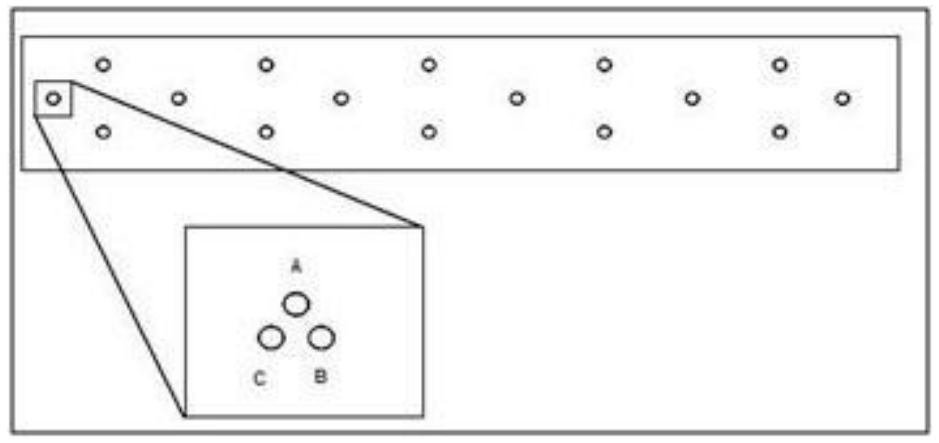

Figura 3. Modelo de distribuição dos sensores no solo nas profundidades de $20 \mathrm{~cm}$ (A), $60 \mathrm{~cm}$ (B) e $120 \mathrm{~cm}$ (C).

As análises químicas do solo nas profundidades de 20, 60 e $120 \mathrm{~cm}$ incluíram teores de Matéria Orgânica, Carbono, Nitrogênio, Potencial Hidrogeniônico, Potássio, Cálcio, Magnésio, Hidrogênio, Alumínio, Fósforo, porcentagem de Saturação de Bases, soma de bases, capacidade de troca catiônica de acordo com a metodologia do Instituto Agronômico de Campinas (Ferreira et al., 1990).
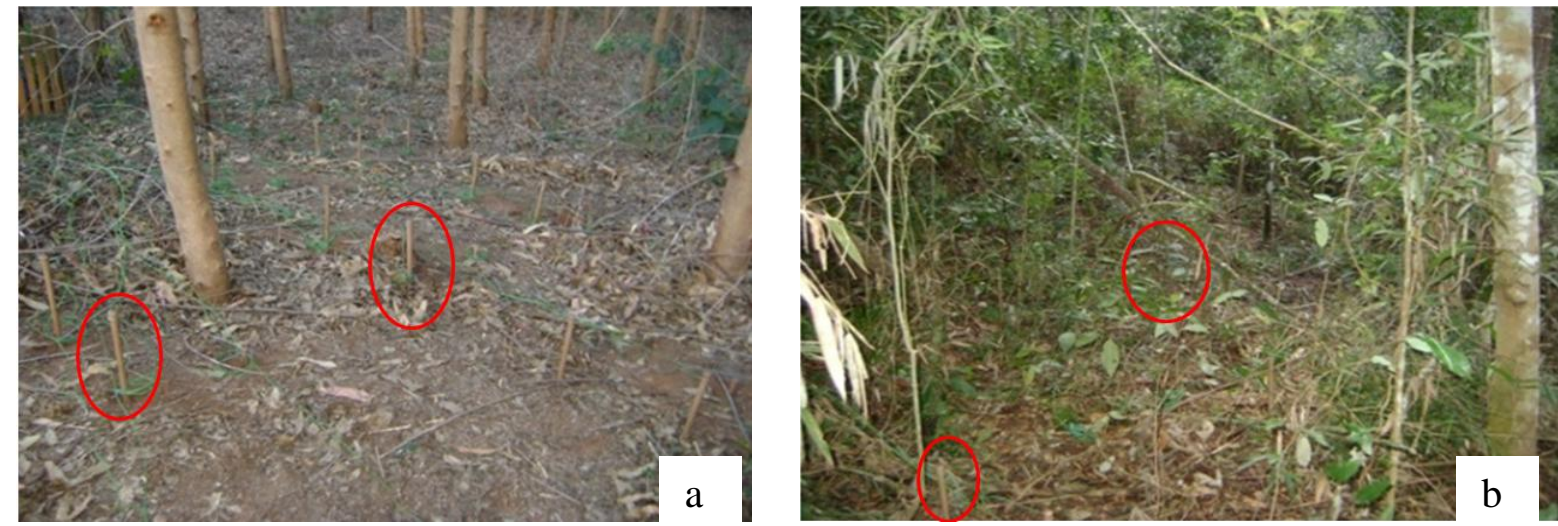

Figura 4. Detalhe dos sensores de umidade nas parcelas de eucalipto (a) e floresta nativa (b).

A infiltração de água no solo foi determinada pelo método do infiltrômetro de anéis concêntricos - IANC, segundo Aguiar (2006), como mostrado na Figura 5. Os valores médios de Infiltração Acumulada (Iac) em mm e Velocidade de infiltração instantânea (VI) em mm/h foram obtidos a partir de três testes de campo em cada tipo de vegetação.

Foi coletada a temperatura radiométrica do solo e da copa das árvores da área experimental de Eucalipto e de floresta nativa por meio de um termômetro digital de infravermelho (modelo TD-971). As medidas foram realizadas semanalmente, entre $11 \mathrm{~h}$ e 12h, que consistiram em apontar o sensor de radiação infravermelha para o solo de cada uma das áreas e para a copa das árvores, sem incluir o fundo do céu e anotar o valor disposto no display. 


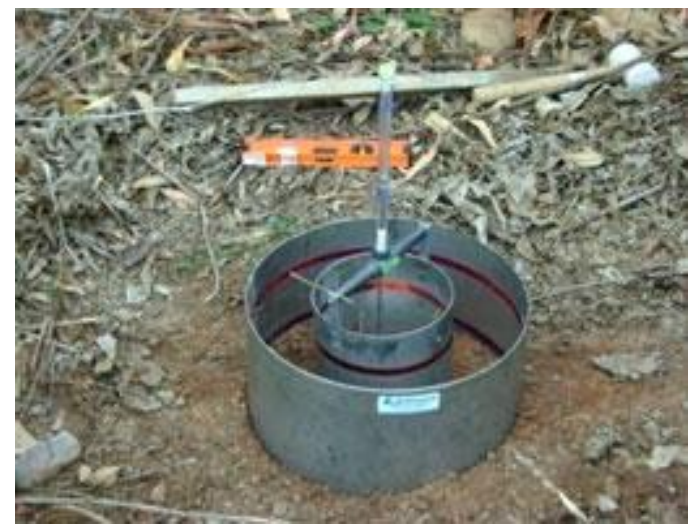

Figura 5. Testes de infiltração na área experimental com o Infiltrômetro de Anéis Concêntricos - IANC.

\subsection{Balanço hídrico climatológico}

O Balanço Hídrico Climatológico foi realizado segundo a metodologia de Thornthwaite e Mather (1955), a partir da planilha eletrônica Balanço Hídrico GD V.3.2-2002 (D’Angiolella e Vasconcellos, 2002), que utiliza informações de temperatura média, precipitação e a capacidade de água disponível no solo (CAD) que serve a uma grande variedade de culturas e diversas aplicações hidrológicas.

A capacidade de água disponível (CAD) utilizada para o balanço hídrico climatológico, segundo Thorthwaite e Mather (1955), independentemente do tipo de solo, adotada para espécies florestais varia entre 150 e $300 \mathrm{~mm}$ (Pereira et al., 2002). Dessa forma, utilizou-se no cálculo do balanço hídrico climatológico $150 \mathrm{~mm}$ de CAD.

Os dados meteorológicos de precipitação $(\mathrm{mm})$ e temperatura do $\operatorname{ar}\left({ }^{\circ} \mathrm{C}\right)$ foram coletados na Estação Meteorológica Automática - A740, operada pelo Instituto Nacional de Meteorologia (INMET, 2009), localizada no município de São Luiz do Paraitinga, a $20 \mathrm{~km}$ da área experimental, em altitude de $870 \mathrm{~m}$ e nas coordenadas $23^{\circ} 13^{\prime} 67^{\prime} \mathrm{S}$ e $45^{\circ} 25^{\prime} 00^{\prime}$ ' W. Os dados de evapotranspiração de referência foram calculados pelo modelo de Penman-Monteith, seguindo os procedimentos propostos por Smith (1991) e Allen et al. (1998).

\section{RESULTADOS E DISCUSSÃO}

\subsection{Características do solo da Fazenda Una}

O solo predominante nas áreas de eucalipto e de floresta nativa na área experimental é um Latossolo Vermelho-Amarelo (EMBRAPA, 1999). Segundo suas frações texturais obtidas pela análise granulométrica (Tabela 1) ele é classificado como de textura argilosa.

Tabela 1. Frações texturais do solo nas áreas de floresta nativa e eucalipto.

\begin{tabular}{|c|c|c|c|}
\hline \multirow{2}{*}{ Área } & \multicolumn{3}{|c|}{ Frações texturais do solo (\%) } \\
\hline & Argila & Areia & Silte \\
\hline Floresta nativa & 65 & 29 & 6 \\
\hline Eucalipto & 58 & 30 & 12 \\
\hline
\end{tabular}

Os valores determinados para a massa específica do solo ( $\rho s)$, das partículas ( $\rho p)$ e de sua porosidade total $(\alpha)$ nas áreas de eucalipto e de floresta nativa nas profundidades de 20 , 60 e $120 \mathrm{~cm}$, são apresentados na Tabela 2, em que se verifica que ambas as áreas têm características semelhantes em termos desses parâmetros. Contudo, destaca-se que a área de eucalipto possui maiores percentuais de silte e de areia (Tabela 1) o que parece estar 
associado com os valores menores de porosidade total, principalmente na camada superficial, quando comparadas com aqueles do solo da área de floresta nativa (Tabela 2).

Tabela 2. Massas específicas do solo e das partículas e porosidade total do solo nas áreas de floresta nativa e eucalipto.

\begin{tabular}{|c|c|c|c|c|c|c|}
\hline \multirow{2}{*}{$\begin{array}{l}\text { Profundidade } \\
\text { (cm) }\end{array}$} & \multicolumn{3}{|c|}{ floresta nativa } & \multicolumn{3}{|c|}{ eucalipto } \\
\hline & $\rho s$ & $\rho p$ & $\alpha$ & $\rho s$ & $\rho p$ & $\alpha$ \\
\hline 20 & 1,16 & 2,47 & 52,8 & 1,24 & 2,37 & 47,9 \\
\hline 60 & 1,27 & 2,42 & 47,7 & 1,29 & 2,48 & 47,9 \\
\hline 120 & 1,14 & 2,54 & 55,2 & 1,12 & 2,52 & 55,7 \\
\hline Média & 1,19 & 2,48 & 51,9 & 1,22 & 2,46 & 50,5 \\
\hline
\end{tabular}

Curvas de retenção de água no solo para as áreas de eucalipto e de floresta nativa na camada de 0 a $120 \mathrm{~cm}$ estão apresentadas nas Figuras 6a e 6b, respectivamente. As equações de regressão, do tipo potencial, entre a umidade volumétrica $(\theta)$ em $\mathrm{m}^{3} \cdot \mathrm{m}^{-3}$ e o potencial mátrico da água no solo ( $\mathrm{T}$ ) em $\mathrm{kPa}$ para a área de floresta nativa (Equação 1) e de eucalipto (Equação 2), mostram um bom ajustamento aos valores medidos e apresentaram coeficiente de determinação $\left(\mathrm{R}^{2}\right)$ próximo de 0,95 .

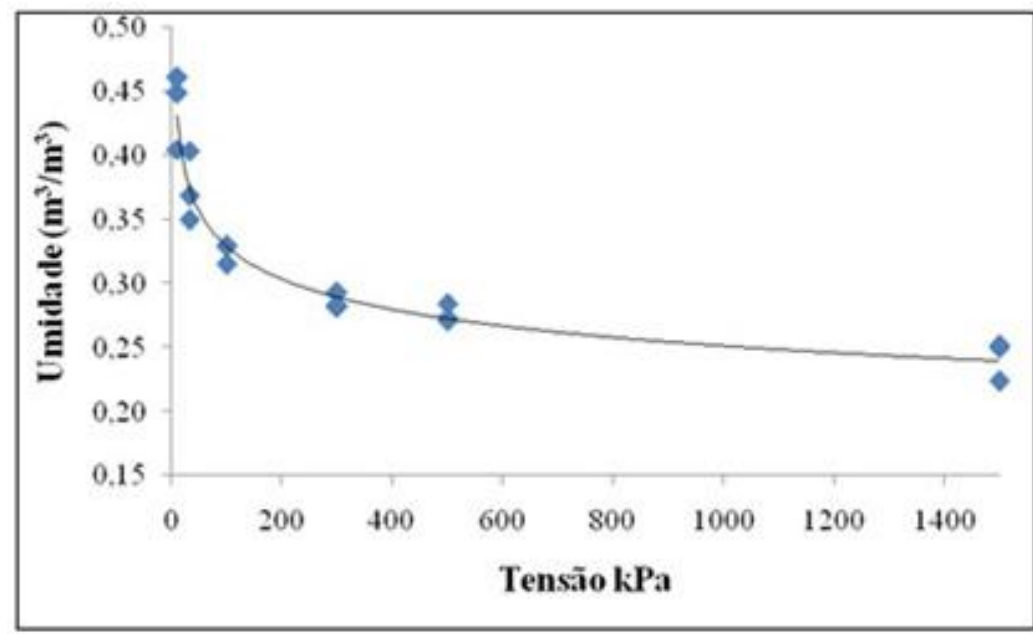

(a) Eucalipto

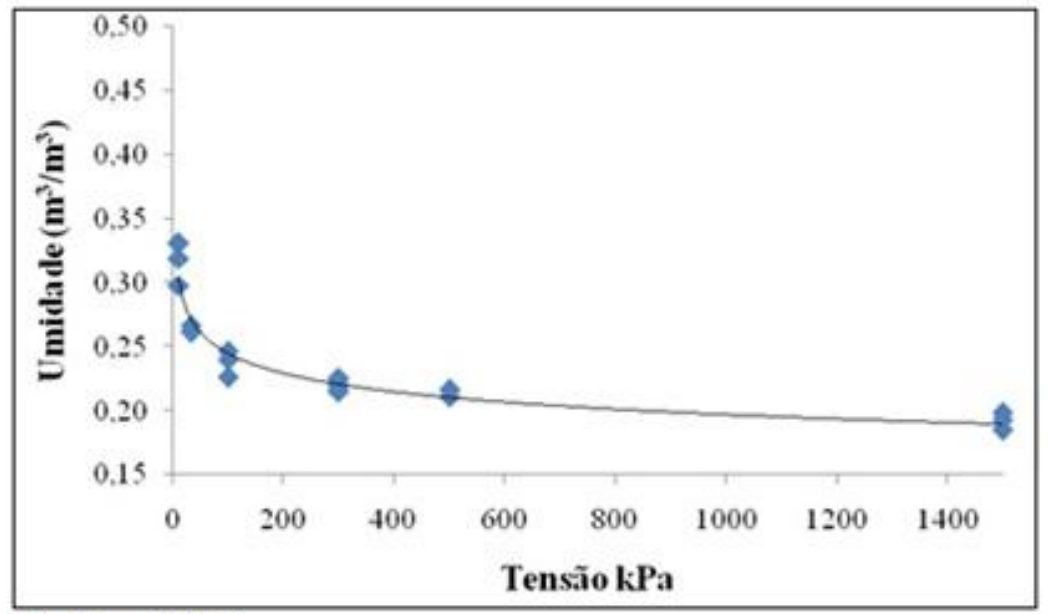

(b) Floresta Nativa

Figura 6. Curvas de retenção da água no solo em parcelas de eucalipto (a) e floresta nativa (b). Qualidade inaceitável, trocar para melhor resolução. 
Floresta nativa

$$
\begin{aligned}
& \theta=0,377 * \mathrm{~T}^{-0,09} \\
& \theta=0,566 * \mathrm{~T}^{-0,11}
\end{aligned}
$$

Eucalipto

em que $\theta$ é a umidade volumétrica $\mathrm{em} \mathrm{m}^{3} \cdot \mathrm{m}^{-3} \mathrm{e}$ T o potencial mátrico da água no solo em $\mathrm{kPa}$.

A Capacidade de Água Disponível (CAD) no solo para a profundidade (z) até $120 \mathrm{~cm}$ para as duas áreas foram calculadas pela Equação 3.

$$
\mathrm{CAD}=\left(\theta_{\mathrm{CC}}-\theta_{\mathrm{PMP}}\right) * z
$$

Os valores da umidade na Capacidade de Campo $\left(\theta_{\mathrm{CC}}\right)$ e no Ponto de Murchamento Permanente $\left(\theta_{\mathrm{PMP}}\right)$, para as duas áreas de cobertura vegetal foram obtidas a partir das Equações 1 e 2.

Os valores determinados para os principais parâmetros químicos do solo das duas áreas estudadas são apresentados na Tabela 3, em que se verifica que as duas áreas estudadas apresentam acidez classificada como muito alta ( $\mathrm{pH}$ até 4,3, segundo Van Raij et al., 1985). Em geral, as duas áreas são semelhantes em termos de características químicas, o que pode ser

\begin{tabular}{|c|c|c|c|c|c|c|c|c|c|c|c|c|c|c|c|}
\hline Amostra & $\underset{\mathrm{CaCl}_{2}}{\mathrm{pH}}$ & $\begin{array}{c}\text { MO } \\
\text { Materia } \\
\text { Orgânica } \\
\text { g/dm }\end{array}$ & $\begin{array}{c}P \\
\text { Fósforo } \\
\mathrm{mg} / \mathrm{dm}^{3}\end{array}$ & $\begin{array}{c}\mathrm{K} \\
\text { Potássio }\end{array}$ & $\begin{array}{c}\text { Ca } \\
\text { Cálcio }\end{array}$ & $\begin{array}{c}\mathrm{Mg} \\
\text { Magnesio } \\
\mathrm{mmol}_{2} / \mathrm{dm}^{2} \text { - }\end{array}$ & $\begin{aligned} & \mathrm{H}+\mathrm{Al} \\
& \text { Hidrogênio } \\
&+ \text { +Aluminio }\end{aligned}$ & $\begin{array}{c}\text { SB } \\
\text { Soma de } \\
\text { Bases }\end{array}$ & $\begin{array}{c}\text { CTC } \\
\text { Cap. Troc. } \\
\text { Cat. }\end{array}$ & $\begin{array}{c}V \\
\text { Sat. por } \\
\text { Bases } \\
\%\end{array}$ & $\begin{array}{c}\text { B } \\
\text { Boro }\end{array}$ & $\begin{array}{l}\mathrm{Cu} \\
\text { Cobre }\end{array}$ & $\begin{array}{c}\mathrm{Fe} \\
\text { Ferro } \\
\mathrm{mg} / \mathrm{dm}^{2}\end{array}$ & $\begin{array}{c}\text { Mn } \\
\text { Manganês }\end{array}$ & $\begin{array}{c}\mathrm{Zn} \\
\text { Zinco }\end{array}$ \\
\hline Flores & 3,7 & 38 & 11 & 1,0 & 2 & 1 & 148 & 4,0 & 152,0 & 3 & 0,29 & 0,7 & 120 & 0,9 & 1,8 \\
\hline Eucalipto & 3,6 & 29 & 10 & 0,6 & 2 & 1 & 133 & 3,6 & 136,6 & 3 & 0,22 & 0,5 & 125 & 0,1 & 0,5 \\
\hline
\end{tabular}
explicado pelo acúmulo de material vegetal na superfície e ciclagem de nutrientes.

Tabela 3. Características químicas do solo das áreas estudadas.

\subsection{Balanço hídrico}

$\mathrm{Na}$ Figura 7 estão apresentados os dados de precipitação pluvial (mm) e temperatura do ar $\left({ }^{\circ} \mathrm{C}\right)$ medidos na área experimental, bem como de evapotranspiração de referência $(\mathrm{mm})$ no período de maio de 2009 a Fevereiro de 2011.

A precipitação total no período foi de $3.115,2 \mathrm{~mm}$, devendo ser destacado que somente no mês de dezembro de 2009 choveu 412,2 $\mathrm{mm}(13,2 \%)$ do total do período. As temperaturas médias mensal máxima ocorreram em fevereiro de $2010\left(23,1^{\circ} \mathrm{C}\right)$ e janeiro de $2011\left(22,2^{\circ} \mathrm{C}\right)$ e as médias mensal mínima em julho de $2009\left(13,9^{\circ} \mathrm{C}\right)$ e junho de $2010\left(13,3^{\circ} \mathrm{C}\right)$. Por outro lado, a evapotranspiração acumulada no período foi de $1792,3 \mathrm{~mm},(57,5 \%)$ da precipitação total no mesmo período, mas como se pode observar a Evapotranspiração não apresentou grandes variações no período.

A Figura 8a mostra o balanço hídrico climatológico para o período de maio de 2009 a abril de 2010. Observa-se que no mês de maio de 2009, o balanço hídrico estava negativo, porém a partir de junho de 2009, começa a reposição da água no solo. Os sensores foram instalados em julho de 2009. Nesse período, as espécies florestais absorvem água de camadas mais profundas. Embora tenha ocorrido uma reposição de água no solo no mês de julho, a maior parte dessa reposição ocorre de outubro de 2009 a janeiro de 2010 . O balanço hídrico climatológico no período indicou um acúmulo de $258,7 \mathrm{~mm}$, evidenciando o excesso hídrico no período de novembro de 2009 até a segunda quinzena de março de 2010.

A Figura 8b apresenta o balaço hídrico climatológico para o período de maio de 2010 a abril de 2011. Observa-se que o balanço hídrico climatológico a partir da segunda quinzena de abril de 2010 até novembro de 2010 ficou negativo, acontecendo à reposição e o excesso a partir de novembro até março de 2011. 


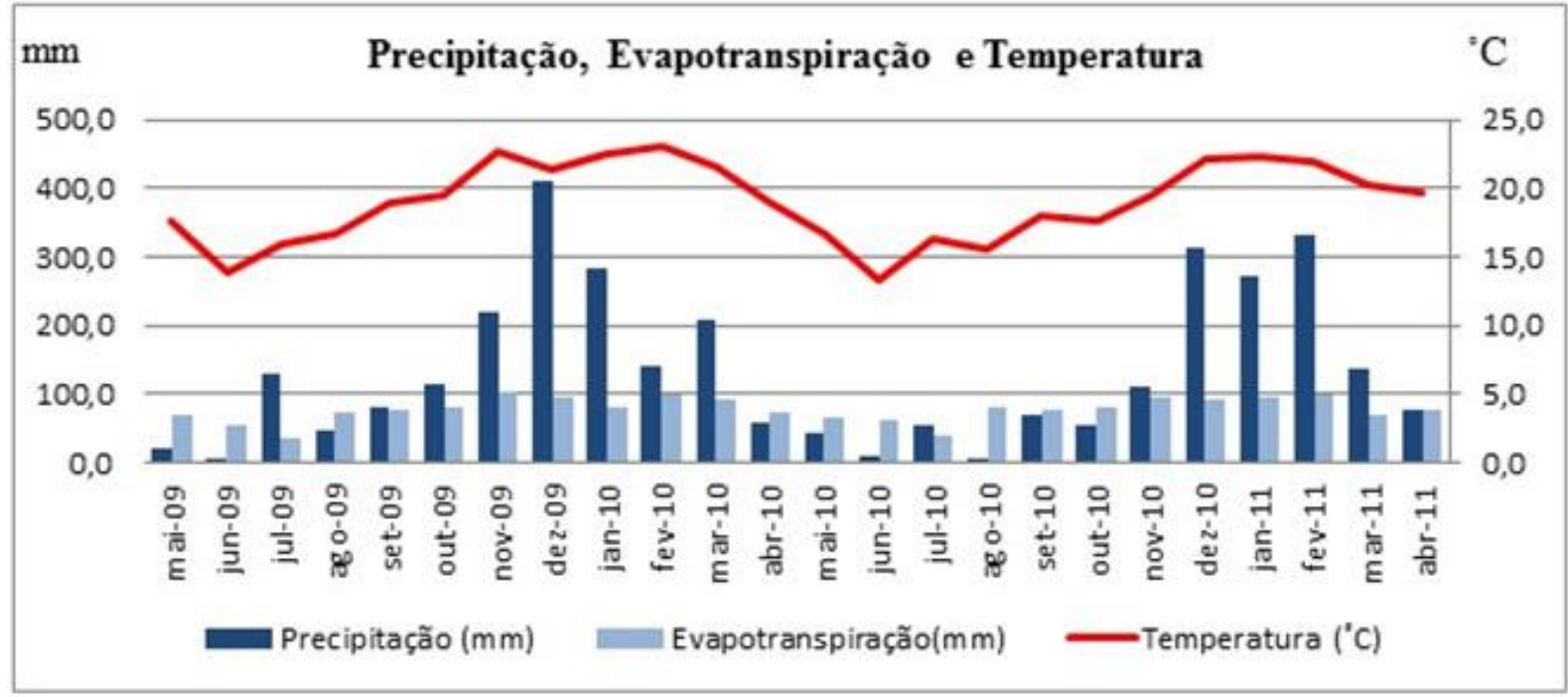

Figura 7. Valores de precipitação pluvial $\left(\mathrm{mm} \cdot \mathrm{mê}^{-1}\right)$, temperatura do $\operatorname{ar}\left({ }^{\circ} \mathrm{C}\right)$ e evapotranspiração de referência $\left(\mathrm{mm} . \mathrm{mês}^{-1}\right)$ na área experimental.
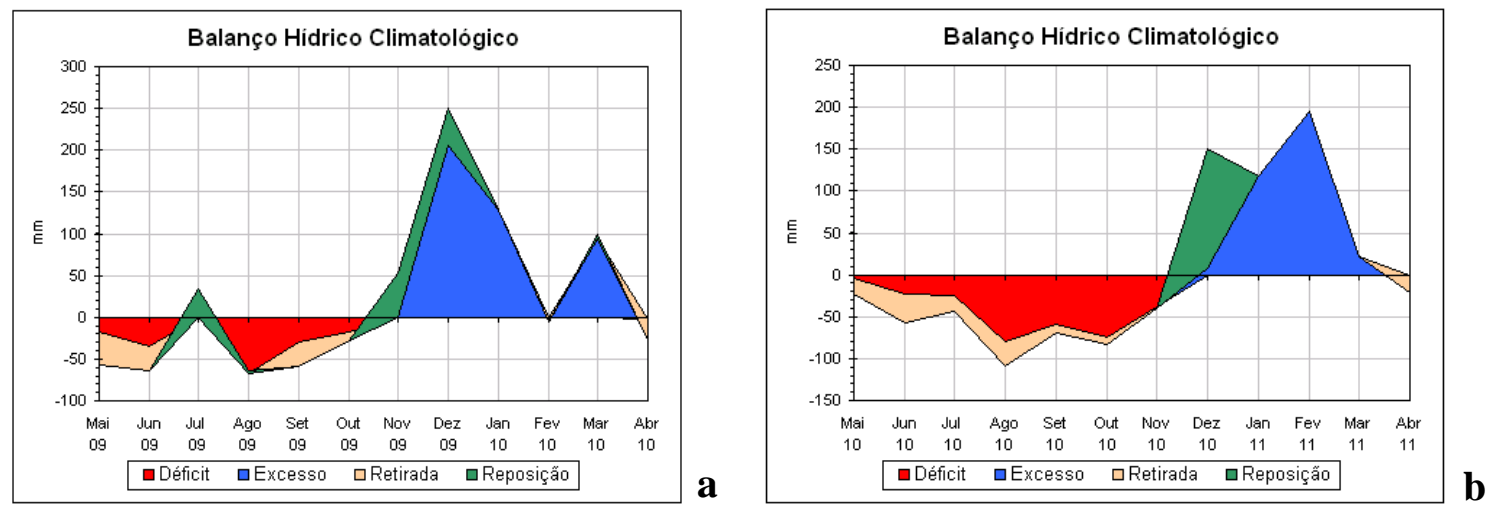

Figura 8. Balanço hídrico climatológico 2009 a 2010 (a) e 2010 a 2011 (b).

\subsection{Capacidade de infiltração da água no solo}

Os testes de infiltração foram realizados no mês de junho, quando o solo apresentava-se com déficit de água no solo, conforme pode ser observado na Figura 8. Na Figura 9 estão apresentadas as curvas da infiltração acumulada e velocidade de infiltração instantânea, respectivamente, para os solos da área de e eucalipto (A1 e B1) e floresta nativa (C1 e D1) em que se pode observar que as duas áreas apresentam ampla capacidade de infiltração, sendo a Velocidade de infiltração básica (VIB) para a área de eucalipto (1600 mm.h-1) e para a floresta nativa (1100 mm.h-1), os quais indicam que é praticamente impossível ocorrer escoamento superficial em qualquer uma das áreas estudadas e por outro lado, os solos dessas áreas são capazes de acumular grandes quantidades de água, pois mesmo com valores excessivos de precipitação em novembro de $2009(412 \mathrm{~mm})$, em dezembro de $2010(311 \mathrm{~mm})$ e fevereiro de 2011 (333 mm), as áreas de eucalipto e floresta nativa não apresentaram sinais de erosão. 

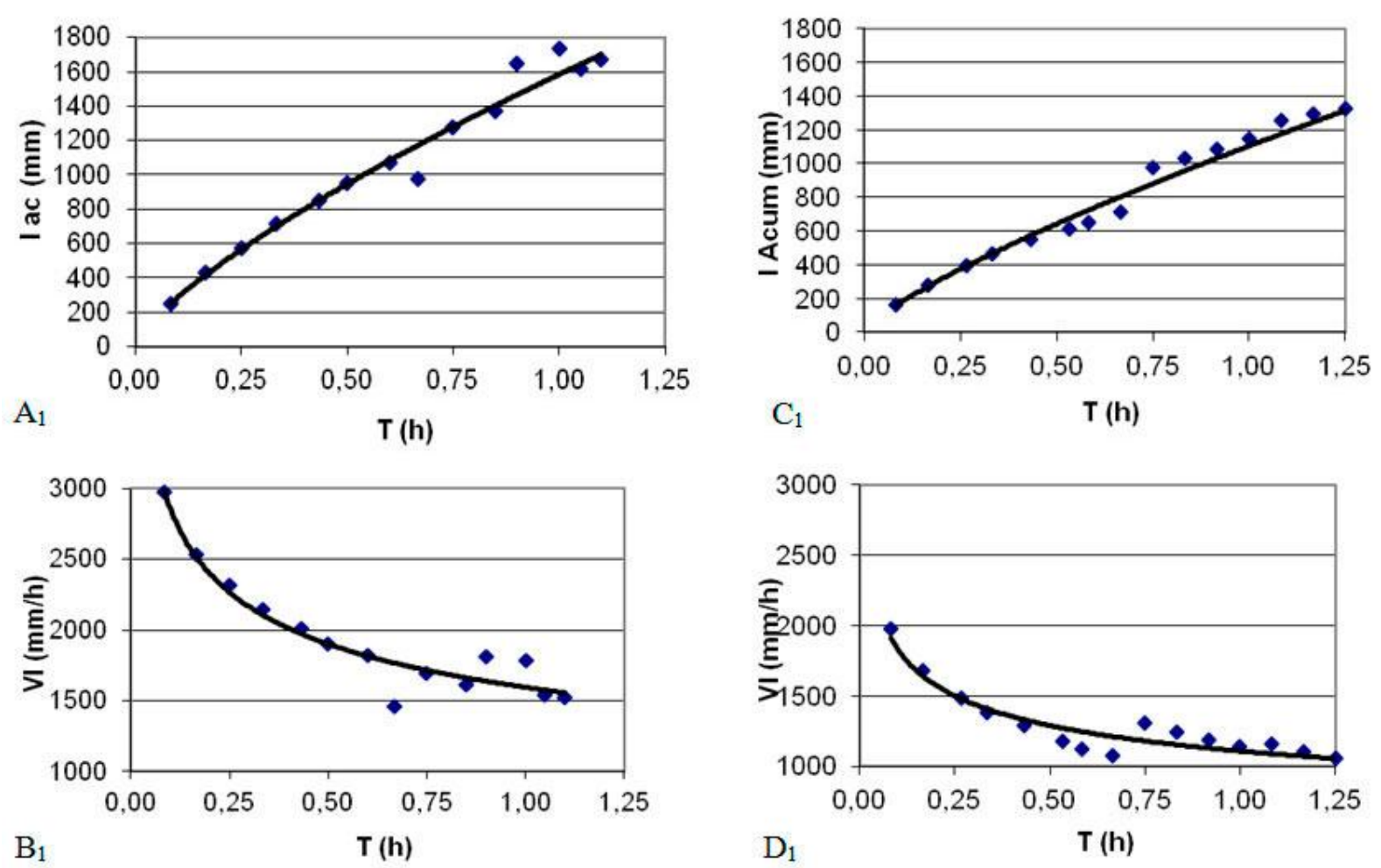

Figura 9. Curvas de Infiltração acumulada (IAC) e Velocidade de Infiltração instantânea (VI) para os solos das parcelas de eucalipto $\left(\mathrm{A}_{1}\right.$ e $\left.\mathrm{B}_{1}\right)$ e floresta nativa $(\mathrm{C} 1$ e $\mathrm{D} 1)$.

As médias de temperatura do solo, da copa e do ar estão dispostas na Figura 10. Em condições de estresse hídrico, a cultura do eucalipto perde menos água por evapotranspiração, pois seus estômatos fecham e ocorre uma economia de água, conforme já observaram Pereira et al. (2006). Contudo, na área estudada, observa-se que a temperatura média na superfície do solo (Figura 10) com eucalipto é maior $\left(\right.$ Tmax $=37^{\circ} \mathrm{C}$ ) que a do solo coberto por floresta nativa (Tmax $=28,4^{\circ} \mathrm{C}$ ). De outro modo a temperatura média da copa das árvores foi menor no eucalipto $\left(\operatorname{Tmax}=28,4^{\circ} \mathrm{C}\right.$ ) do que na floresta nativa $\left(\operatorname{Tmax}=29,6^{\circ} \mathrm{C}\right.$ ), indicando que o eucalipto evapotranspira mais que a floresta nativa e assim, tem maior troca de calor e apresentou copa com menor temperatura. Por outro lado observou-se também que a floresta nativa apresenta uma temperatura mais constante para solo (Tmed $=21,9^{\circ} \mathrm{C}$ ) e para copa $\left(\right.$ Tmed $\left.=22,8^{\circ} \mathrm{C}\right)$, do que o eucalipto que apresentou $\left(\right.$ Tmed $\left.=27,5^{\circ} \mathrm{C}\right)$ para o solo e $($ Tmax $=$ $22,0^{\circ} \mathrm{C}$ ) para a copa. Dessa forma, ocorreu maior perda de água na área de eucalipto em comparação com a área de floresta nativa. 

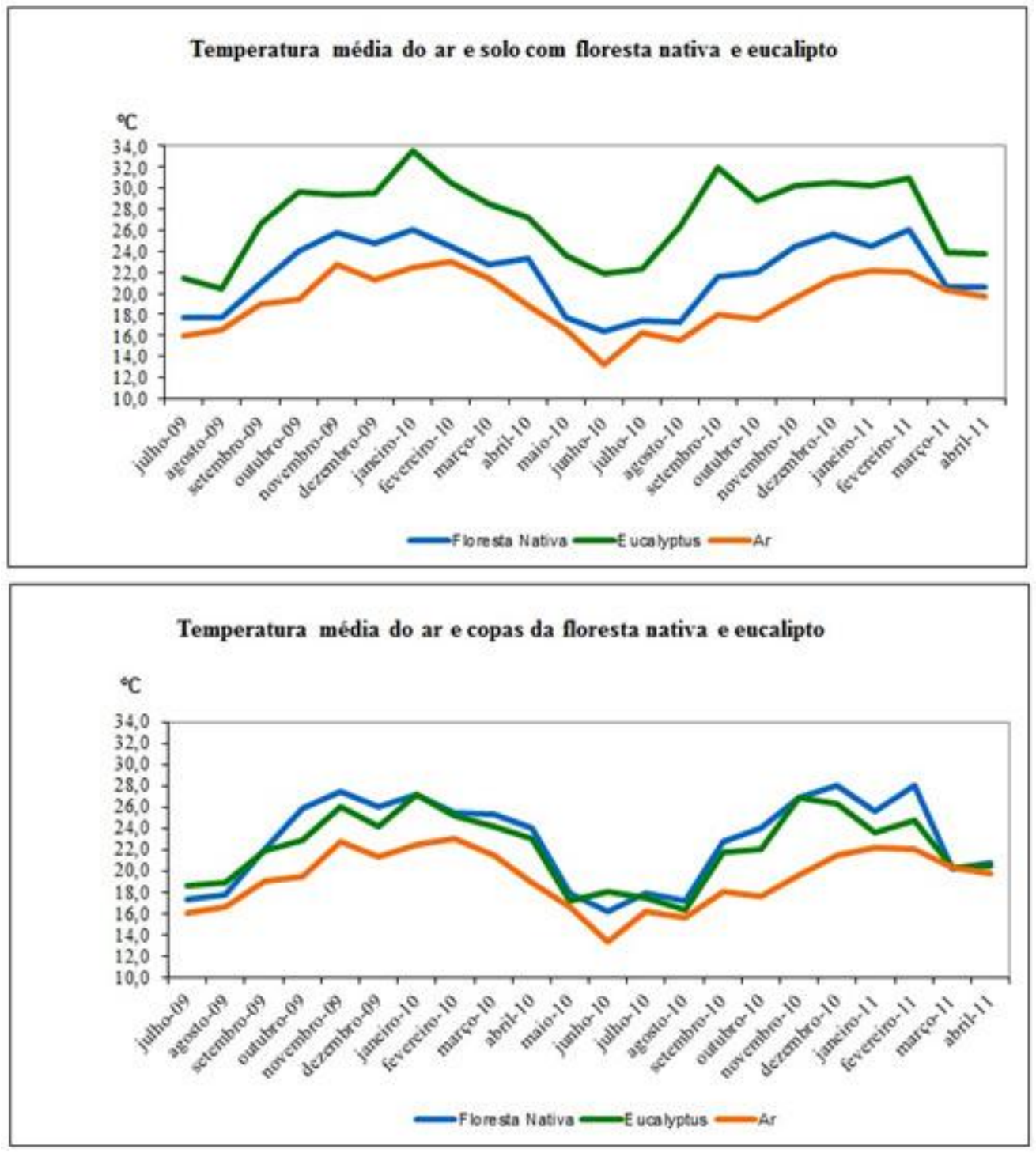

Figura 10. Temperatura média do solo, ar e copa das árvores de floresta nativa e eucalipto.

\subsection{Variação da umidade do solo}

A Figura 11 apresenta os valores da umidade medida no solo nas profundidades de 20, 60 e $120 \mathrm{~cm}$ nas áreas de floresta nativa e de eucalipto. Pode-se observar que houve diferença na umidade do solo para os dois grupos vegetais durante o período de estudo. Em geral, as variações acompanharam o regime de chuvas indicando que a água penetrou e se armazenou no solo. Essas mudanças na umidade ao longo do tempo foram mais pronunciadas na cultura de eucalipto do que na floresta nativa. A profundidade até $20 \mathrm{~cm}$ foi a que apresentou maior alteração no padrão de umidade, seguida pela camada até $60 \mathrm{~cm}$ e por último a camada até $120 \mathrm{~cm}$, que manteve a umidade mais constante ao longo do tempo. As variações de umidade na camada até $20 \mathrm{~cm}$ e de 20 a $60 \mathrm{~cm}$ na cultura do eucalipto podem ser devido ao fato de o sistema radicular composto por raízes finas $(<2 \mathrm{~mm})$ se concentrar até $50 \mathrm{~cm}$ de profundidade, com predominância de quase $58 \%$ dessas raízes até a profundidade de $20 \mathrm{~cm}$ (Witschoreck et al., 2003) e também, devido a camada de 0 a $20 \mathrm{~cm}$ se constituir a interface solo- ar. 

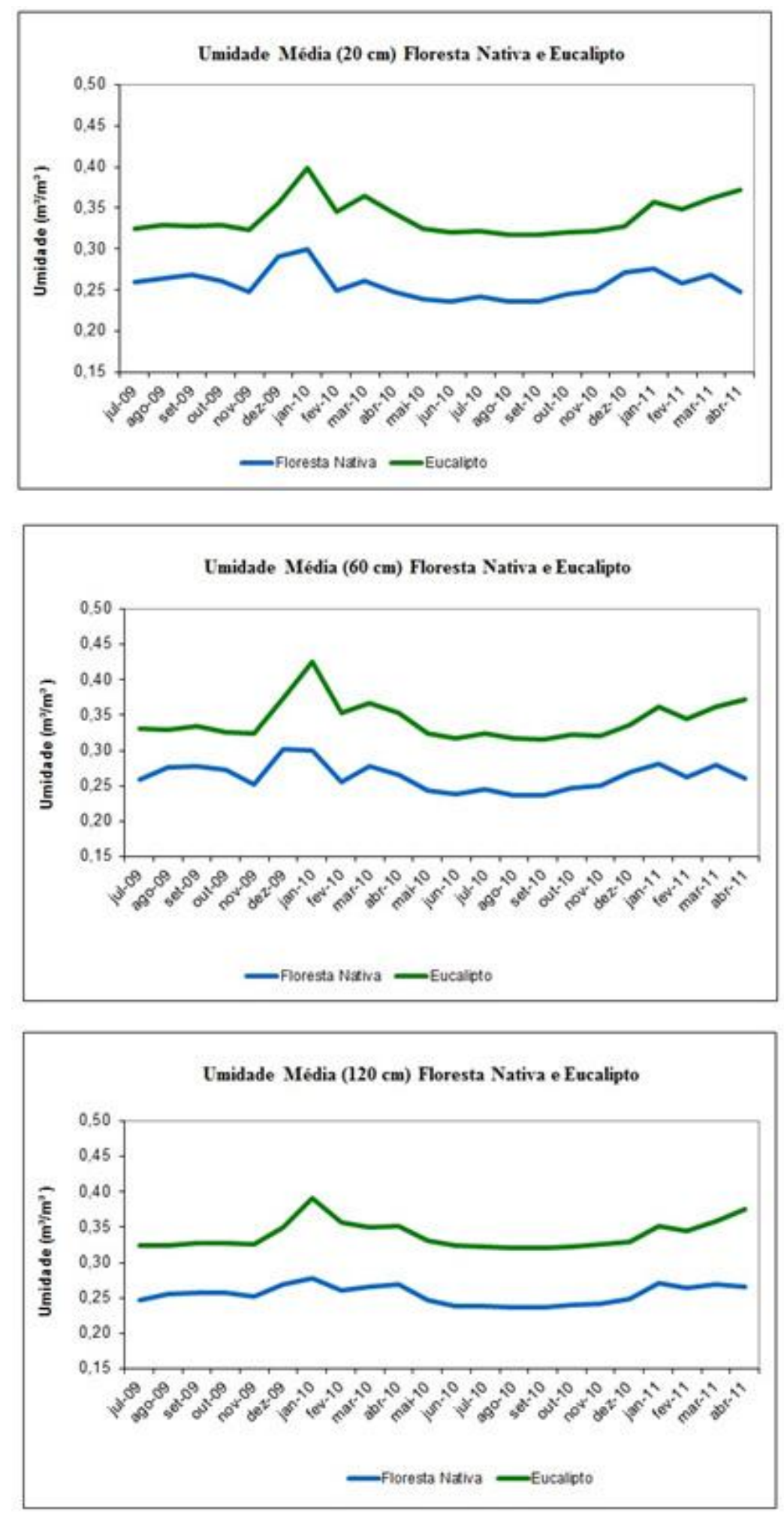

Figura 11. Umidade média mensal para as camadas de 20, 60 e $120 \mathrm{~cm}$ no solo com floresta nativa e eucalipto.

Por outro lado, a menor variação de umidade na floresta nativa se deve ao fato desta possuir espécies vegetais diversificadas com diferentes sistemas radiculares e, por conseguinte com necessidades variadas de água e menor variação de temperatura.

Os valores da umidade na Capacidade de Campo $\left(\theta_{\mathrm{CC}}\right)$ e no Ponto de Murchamento Permanente $\left(\theta_{\mathrm{PMP}}\right)$, para as duas áreas foram respectivamente: 
Floresta nativa: $\theta_{\mathrm{CC}}=0,304 \mathrm{~m}^{3} \cdot \mathrm{m}^{-3} ; \theta_{\mathrm{PMP}}=0,190 \mathrm{~m}^{3} \cdot \mathrm{m}^{-3}$;

Eucalipto: $\theta_{\mathrm{CC}}=0,439 \mathrm{~m}^{3} \cdot \mathrm{m}^{-3} ; \theta_{\mathrm{PMP}}=0,253 \mathrm{~m}^{3} \cdot \mathrm{m}^{-3}$.

Dessa forma, a CAD no solo até a profundidade de $120 \mathrm{~cm}$ é de $137 \mathrm{~mm}$ para o solo da área com floresta nativa e de $223 \mathrm{~mm}$ para área com eucalipto. Embora as duas áreas apresentem características físicas de solo argiloso semelhantes, a CAD na área de eucalipto é cerca de $63 \%$ superior àquela da Mata Nativa.

Na Figura 12 estão apresentados os valores médios mensais de umidade do solo nas áreas de floresta nativa e eucalipto nas profundidades de 20, 60 e $120 \mathrm{~cm}$, comparados com valores da umidade na CC e no PMP. Observa-se que os valores mensais médios de umidade em cada uma das profundidades estudadas não variaram muito entre si. A umidade do solo na profundidade de $120 \mathrm{~cm}$ no período mais chuvoso (novembro/2009 a fevereiro/2010) ficou com as médias de umidade mais baixa, fato que indica que a água infiltrada no solo, nesse período, ainda não havia alcançado essa profundidade. Outra observação a ser feita é o fato que em nenhum momento a Capacidade de Campo e o Ponto de Murchamento Permanente foram atingidos.
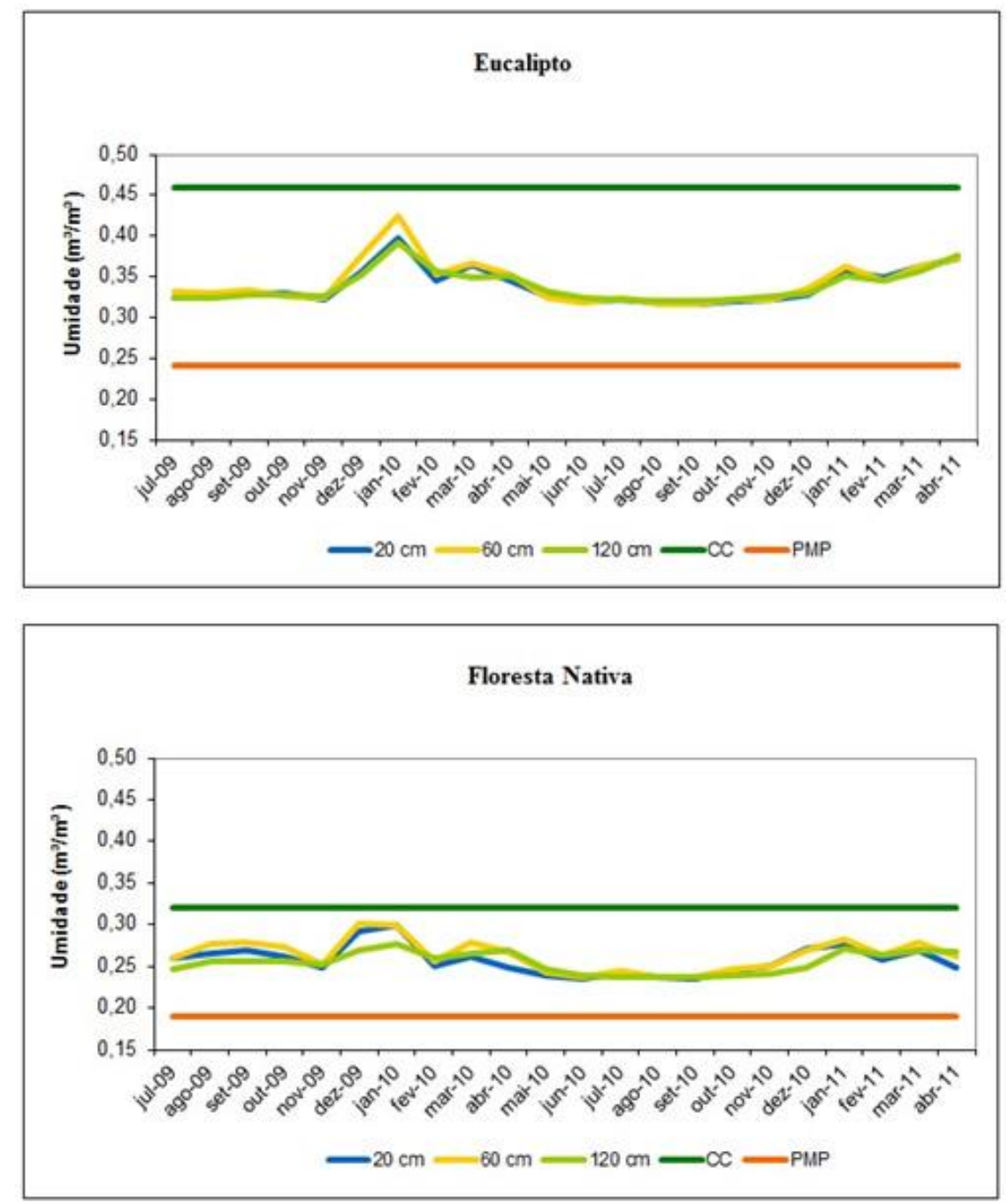

Figura 12. Valores de umidade média mensal do solo nas profundidades de 20,60 e $120 \mathrm{~cm}$ nas áreas de floresta nativa e eucalipto comparados aos valores de umidade na capacidade de campo e no ponto de murchamento permanente. 


\section{CONCLUSÃO}

O objetivo de avaliar a distribuição e o armazenamento de água no perfil do solo, em áreas pareadas plantadas com Eucalyptus em fase de crescimento (6 anos) e vegetação natural em fase de regeneração (mais de 20 anos), foi atingido com auxílio das metodologias adotadas de mensuração da umidade do solo e de análise comparativa com dados meteorológicos obtidos no mesmo período e resultados das análises de solo.

As áreas pareadas, apesar de próximas e de possuírem a mesma declividade e faceamento (ou aspecto), apresentaram características físicas do solo diferentes, principalmente com relação à capacidade de armazenamento de água. Essas características podem ser responsáveis, total ou parcialmente, pelas diferenças de comportamento da água no solo apresentadas nos resultados desta pesquisa.

Outro aspecto importante para explicar essas diferenças é a disposição das copas das arvores, que no caso da floresta nativa se mostra mais densa e fechada permitindo maior interceptação da precipitação e uma infiltração mais lenta da água no solo, uma menor variação de temperatura entre solo e copa das árvores. Já a cobertura de Eucalyptus se mostra mais espaçada e menos densa, mas sobre um solo que possui características físicas que permitem maior infiltração e armazenamento de água e embora tenha uma maior variação de temperatura entre o solo e copa das árvores, a maior disponibilidade de água promoveu maior evapotranspiração no eucalipto, diminuindo a temperatura da copa das árvores. Essa combinação de fatores pode explicar o fato de não ter sido observada a ocorrência de erosão por escoamento superficial, nas duas áreas, já que toda a água precipitada infiltrou e armazenou no solo.

$\mathrm{O}$ uso de sensores de umidade se mostrou eficiente para a mensuração em diferentes profundidades de forma prática e rápida refletindo a entrada e a saída de água do solo em momentos de precipitação e de seca.

Os resultados desta pesquisa fornecem indícios importantes sobre diferenças no comportamento da água no solo em áreas cobertas com floresta nativa e Eucalyptus. Por essa razão sugere-se que novos estudos com maior abrangência geográfica e utilizando diferentes combinações de áreas pareadas, em que estejam incluídas diferentes declividades, faceamentos e tipos de solo, devam ser realizados para aumentar o conhecimento sobre as diferenças observadas.

\section{AGRADECIMENTOS}

Ao CNPq pelo apoio ao projeto Comportamento da Água no Solo sob Cobertura Vegetal de Eucalipto e de Essências Florestais Nativas, Processo No 480990/2007-7. À empresa Fibria S.A. pelo acesso à área de estudo, Fazenda Una.

\section{REFERÊNCIAS}

AGUIAR, L. S. G. Estimativa do escoamento superficial a partir de testes de infiltração na bacia hidrográfica do Ribeirão Itaim. 2006. 102 f. Dissertação (Mestrado em Ciências Ambientais) - Universidade de Taubaté, Taubaté, 2006.

ALlEN, R. G.; PEREIRA, L. S.; RAES, D.; SMITH, M. Crop evapotranspiration. Guidelines for predicting crop water requirements. Rome: FAO, 1998. 300p. (FAO: Irrigation and Drainage Paper, 56). 
BATISTA, G. T.; TARGA, M. S.; DIAS, N. W.; CATELANI, C. S. Modelo de banco de dados ambientais georreferenciados voltado à recuperação e preservação de recursos hídricos de uma bacia de médio porte, o modelo da bacia do rio Una, Paraíba do Sul, SP. SIMPÓSIO BRASILEIRO DE RECURSOS HÍDRICOS, 16., 2005, João Pessoa. Anais... Rio de Janeiro: ABRH, 2005. Vol. 1. p. 1-16. Disponível em: <http://www.agro.unitau.br:8080/dspace/bitstream/2315/63/1/Una_SBRH_dspace.pdf>. Acesso em: dez. 2013.

COOPERATIVA DE SERVIÇOS, PESQUISAS TECNOLÓGICAS E INDUSTRIAIS CPTI. Plano das Bacias hidrográficas do rio Paraíba do Sul. 2004. Disponível em: <http:www.comiteps.sp.gov.br>. Acesso em: 10 maio 2007.

D’ANGIOLELlA, G. L. B.; VASCONCELlOS, V. L. D. Cálculo do balanço hídrico climatológico com diferentes métodos para estimativa da evapotranspiração potencial, em planilhas Excel ${ }^{\mathrm{TM}}$. In: CONGRESSO BRASILEIRO DE METEOROLOGIA, 12. 2002, Foz do Iguaçu. Anais... Foz do Iguaçu: SBMET, 2002. 1 CD-Rom.

EMBRAPA. Centro Nacional de Pesquisa de Solo. Sistema brasileiro de classificação de solos. Rio de Janeiro, 1999. 412p.

FERREIRA, M. E.; CRUZ, M. C. P.; FERREIRA JR., M. E. Avaliação da fertilidade empregando o sistema IAC de analise de Solo. Jaboticabal: UNESP/FCAV, 1990. (Boletim Técnico)

GEE, G. W.; BAUDER, J. W. Particle-size analysis. In: KLUTE, A. (Ed.). Methods of soil analysis. Part 1. Physical and mineralogical methods. Madison: American Society of Agronomy, 1986. p. 383-411.

INSTITUTO NACIONAL DE METEOROLOGIA - INMET. Dados meteorológicos. Plataforma de coleta de dados A740. 2009. Disponível em: 〈http: www.inmet.gov.br〉. Acesso em: mar. 2011.

KIEHL, E. J. Manual de edafologia: relações solo-planta. São Paulo: Ceres, 1979. 264p.

KLUTE, A. (Ed.). Methods of soil analysis. Part 1. Physical and mineralogical methods. Madison: American Society of Agronomy, 1986. p. 1188.

LEMOS, C. F. Caracterização e variabilidade climática do Vale do Paraíba - SP. 2000. 120f. Dissertação (Mestrado em Ciências Ambientais) - Universidade de Taubaté, Taubaté, 2000.

LIMA, W. P. Impacto ambiental do eucalipto. 2. ed. São Paulo: Ed. da Universidade de São Paulo, 1996. $301 \mathrm{p}$.

PEREIRA, A. R.; ANGElOCCI, L. R.: SENTELHAS, P. C. Agrometeorologia: fundamentos e aplicações práticas. Guaíba: Agropecuária, 2002.

PEREIRA, M. R. R.; KLAR, A. E.; SILVA, M. R.; SOUZA, R. A.; FONSECA, N. R. Comportamento fisiológico e morfológico de clones de Eucalyptus urograndis submetidos a diferentes níveis de água no solo. Irriga, Botucatu, v. 11, n. 4, p. 518-531, out./dez. 2006.

REICHARDT, K.; TIMM, L. C. Solo, planta e atmosfera: conceitos, processos e aplicações. 2. ed. Barueri: Manole, 2004. 478 p. 
SMITH, M. Report on the expert consultation on procedures for revision of FAO guidelines for predictions of crop water requirements. Rome: FAO, 1991. 45p.

THORNTHWAITE, C. W.; MATHER, J. R. The water balance: publications in climatology. New Jersey: Drexel/Institute of Technology, 1955. 104 p.

TRACOM IMPORTAÇÃO EXPORTAÇÃO E COMÉRCIO LTDA. Watermark sensores para monitoramento da umidade do solo. 2004. Disponível em: <http://www.tracom.com.br/Irrometer/pdf/ watermark.pdf>. Acesso em: 21 maio 2009.

VAN RAIJ, B.; CANTARELlA, H.; QUAGGIO, J. A.; FURLANI, A. M. C. Recomendação de adubação e calagem para o estado de São Paulo. Campinas: Instituto Agronômico de Campinas, 1985. (Boletim Técnico, 100).

WITSCHORECK, R.; SCHUMACHER, M. V.; CALDEIRA, M. V. W. Estimativa da biomassa e do comprimento de raízes finas em Eucalyptus urophylla S.T. Blake no município de Santa Maria-RS. Revista Árvore, v. 27, n. 2, p. 177-183, 2003. http://dx.doi.org/10.1590/S0100-67622003000200008 